\title{
CAPACITACIÓN Y ADIESTRAMIENTO PARA EL TRABAJO EN EL DERECHO MEXICANO
}

[Labor Qualification and Training in the Mexican Law]

\section{María Aurora de la Concepción Lacavex Berumen* Universidad Autónoma de Baja California}

\begin{abstract}
RESUMEN
Los conocimientos, habilidades, aptitudes y actitudes que los trabajadores tienen para el desempeño de su trabajo es un tema de reciente interés para patrones, trabajadores y autoridades del trabajo. La historia nos refiere cómo se ha pasado desde el aprendizaje romano y medieval, hasta llegar a la obligación patronal de proveer capacitación y adiestramiento, en la búsqueda de productividad y competitividad

Palabras Clave

Capacitación - Adiestramiento Obligación patronal - Opinión de los destinatarios.
\end{abstract}

\begin{abstract}
The workers' knowledge, skills, abilities and attitude to do their job is a topic that has recently interested employers, workers and labor authorities. History tells us about the process education has undergone from Roman and Medieval learning to the employer's obligation to provide training to achieve more productivity and to be more competitive.

KeYwORDS

Qualification - Training - Employer's Obligation - The Beneficiary's Opinion.
\end{abstract}

RECIBIDO el 18 de junio y ACEPTADo el 30 de noviembre de 2013

* Profesora de la Facultad de Derecho, campus Mexicali, de la Universidad Autónoma de Baja California; Doctora en Derecho por la misma institución. Integrante del Cuerpo Académico "Estudios Jurídicos”. Dirección postal: Mimiahuapan n.o 1800, Fracc. Calafia, Mexicali, B.C., México. C.P. 21040. Correo electrónico: axevacal@ uabc.edu.mx y axevacal@hotmail.com 


\section{INTRODUCCIÓN}

Las necesidades básicas de los seres humanos son: alimentación diaria suficiente para producir la energía requerida para vivir y trabajar; vestido, ropa y calzado adecuados y limpios para protegerlos contra la intemperie; alojamiento, que dé abrigo en condiciones saludables, dotado de los servicios básicos; seguridad, protección contra la violencia, el desempleo, la vejez y las enfermedades, servicios como agua potable, saneamiento, energía eléctrica, medios de transporte y educación ${ }^{1}$.

El disfrute de esos satisfactores representa calidad de vida y si estos mejoran, la calidad de vida mejora también.

Para elevar la calidad de vida de una comunidad, ésta tiene que realizar un esfuerzo conjunto de autoridades y ciudadanos, tendiente a maximizar el rendimiento sustentable de sus recursos. Entre los factores que deben estar presentes, es el trabajo, representado en el empleo digno.

La productividad es la relación entre producción e insumos. La productividad en un centro de trabajo se ve afectada por factores externos e internos. Entre los factores externos se cuenta la disponibilidad de materias primas, políticas fiscales, infraestructura existente. Por lo general están fuera del control de los patrones. Entre los factores internos son de considerarse las instalaciones, el equipamiento, la organización, la mano de obra.

Es derecho del patrón lograr que el tiempo de trabajo se aproveche adecuadamente y se reduzca al máximo el tiempo improductivo, si se considera que jornada de trabajo es el tiempo que el trabajador está a disposición del patrón para realizar el trabajo para el cual fue contratado. Para alcanzar el mejor de los resultados e incrementar la productividad de los centros de trabajo, resulta fundamental, la capacitación y el adiestramiento que los trabajadores reciben, es decir, la formación para el trabajo.

\section{ANTECEDENTES HistóRICOS}

Los romanos organizaron el aprendizaje como un convenio entre el padre del aprendiz y el maestro que enseñaría un oficio. De igual forma, los dueños de los esclavos acostumbraron entregarlos a una persona, durante cierto tiempo, a fin de que los adiestrara en un oficio o arte, debiendo aquellos prestar sus servicios a quien le proporcionaba la instrucción. Esta costumbre se extendió hasta la época del Justiniano. Los Digesta y el Fuero Juzgo contienen textos sobre aprendizaje, que atenúan la responsabilidad

\footnotetext{
${ }^{1}$ Kanawaty, George, Introducción al estudio del trabajo (México, Organización Internacional del Trabajo - Noriega Editores. 2006), p. 3.
} 
de patrono que solía castigar con dureza a un aprendiz. Las Partidas y los estatutos de las antiguas corporaciones de oficios regulaban las obligaciones y derechos de los aprendices y el número de éstos. En España el contrato de aprendizaje fue obligatorio hasta 1813. También la Novisima Recopilación contenía disposiciones sobre esta materia² 2

Los gremios de la Edad Media lo fueron de comerciantes y de artesanos. Los gremios de comerciantes, llamados "gildas" o "hansa" en los países de habla germana, y caritates ofraternitates en los países latinos, originalmente se agruparon para protegerse mutuamente en sus viajes por diversos países. Posteriormente ejercieron ciertos derechos y poderes sobre el comercio en sus propias ciudades, que les eran conferidos por el señor feudal.

Los gremios de artesanos, conocidos en Francia como "corporations de métier", "arte" en Italia y "Zünff" o "Innung" en Alemania, surgieron a principios del siglo XII. Este tipo de gremios apareció cuando un grupo de artesanos pertenecientes a un mismo oficio se agruparon para defender sus intereses. En algunos casos tuvieron una motivación religiosa como la creación de cofradías para venerar a otro patrón. Los miembros se dividían en tres clases: maestros, oficiales y aprendices. El maestro era un pequeño propietario: poseía las materias primas, las herramientas necesarias y vendía los productos para su propio beneficio. Los oficiales y aprendices vivían en la casa del maestro. Los aprendices, que estaban iniciándose en su profesión, aprendían con el maestro y recibían por su trabajo sólo comida y alojamiento. Cuando un aprendiz había concluido su aprendizaje se convertía en oficial y pasaba a recibir sueldo fijo. Con el tiempo, el oficial podía convertirse, a su vez, en maestro, tras realizar un trabajo concreto que le servía para superar el examen que los maestros le proponían y demostrar su capacidad. El trabajo se denominaba obra maestra. Pero los maestros preferían no aumentar la competencia, por lo que las condiciones para convertirse en maestro eran cada vez más difíciles de conseguir, reduciéndose el ingreso a miembros de pocas familias.

A partir del siglo XIV las condiciones se hicieron tan estrictas que era casi imposible acceder al rango de maestro.

El aprendizaje fue una de las instituciones fundamentales del sistema gremial medieval. En el sistema corporativo gremial medieval las relaciones entre aprendiz y el maestro tenían casi como la única preocupación la formación profesional. Suponía la convivencia de maestros y pupilos e involucraba una delegación de poderes comprendidos en la patria potestad. El aprendizaje

${ }^{2}$ Charny, Hugo, voz “Aprendiz”, en Enciclopedia Jurídica Omeba (Buenos Aires, Bibliográfica Omeba. Driskill, 1979), I,A. p. 745. 
era el modo de transmitir, de generación en generación, los secretos que guardaba cada manualidad.

El aprendiz tenía la seguridad de que adquiriría los conocimientos necesarios y de que llegaría a compañero y a maestro; además por regla general, el aprendiz sustituía al maestro en el taller, lo que era una seguridad para el futuro. Fue práctica común hasta el siglo XVIII y la Revolución Industrial, cuando fue reemplazado por el sistema fabril. Con la decadencia de las corporaciones se agravó la situación de los aprendices y de los compañeros, los años de aprendizaje y de compañerismo crecieron y la corporación negaba el permiso para la apertura de nuevos talleres.

La "Ley Le Chapelier" de 1791 suprimió y prohibió en Francia la sindicalización obrera y el Código Penal francés de 1810 estableció el delito de coalición ${ }^{3}$ que tuvieron como consecuencia que los trabajadores, que fueron declarados libres e iguales en terreno político, se encontraran desamparados y solos frente a un capitalismo que cada vez se hacía más poderoso. Miles de trabajadores cayeron en la miseria, ante la impasible mirada del Estado, bajo el principio de "laissez faire, laissez passer". El maquinismo permitió que en los centros de trabajo se diera cabida a la mano de obra no calificada, lo que tuvo como consecuencia, que debido a los raquíticos salarios de los jefes de familia, ingresaran a laborar los demás integrantes de la misma, percibiendo salarios todavía inferiores y teniendo que renunciar al natural deseo y necesidad de una educación completa.

Este liberalismo surgido con la Revolución Francesa, proclamó la libertad de trabajo - libertad de oferta y demanda- y suprimió la escala gremial. Así, se operó una transformación, convirtiéndose el aprendiz en obrero. Esto llevó a que se cometieran excesos de toda índole, hasta que los obreros, unidos bajo el denominador común del proletariado, comenzaran a organizarse sindicalmente y a luchar por derechos y mejoras.

Lo anterior llevó a que, muchos años después, cuando empezaron a surgir las legislaciones del trabajo, se regulara el trabajo de las mujeres y de los menores y el aprendizaje, bajo la óptica moderna.

La Constitución de Weimar, de junio de 1919, impuso la asistencia obligatoria a cursos profesionales complementarios hasta la edad de 18 años.

En 1939, en La Habana, en la Segunda Conferencia de los Estados Americanos, miembros de la Organización Internacional del Trabajo, se destacó la necesidad de que las empresas de los países que no disponían de un número suficiente de escuelas profesionales, asumieran los gastos de for-

${ }^{3}$ Cázares García, Gustavo, Derecho de la seguridad social (México, Porrúa, 2001), p. 10. 
mación profesional de cierta cantidad de trabajadores jóvenes, en proporción al número de personal.

Actualmente, la formación profesional, que anteriormente se desarrollaba por medio del aprendizaje, se logra en los de centros docentes e impartiendo cursos especiales de capacitación y perfeccionamiento.

La mecanización ya no requiere una habilidad manual adquirida por medio de una enseñanza larga y penosa.

La industria, el comercio y los servicios modernos necesitan una inteligencia despierta y conocimientos más extensos y generales que permitan al obrero comprender los procedimientos de fabricación cada vez más complejos.

\section{NORMATIVIDAD INTERNACIONAL}

La Organización Internacional del Trabajo es una institución encargada de promover el progreso social, condición necesaria para alcanzar un desarrollo socioeconómico armonioso. Fue creada en virtud del "Tratado de Paz de Versalles" en 1919, al mismo tiempo que la Sociedad de las Naciones, de la que procede como órgano autónomo. Sus bases se encuentran en la Parte XIII del Tratado referido. En 1946 pasó a ser el primer organismo especializado de la Organización de las Naciones Unidas. México forma parte de este organismo internacional desde 1931 al ser admitido el 12 de septiembre de dicho año.

La Organización Internacional del Trabajo adoptó en la Conferencia General convocada en Ginebra el 5 de junio de 1974, el Convenio 140, relativo a la Licencia pagada de estudios. México es miembro de la Organización Internacional del Trabajo desde el 12 de octubre de 1931, por lo que este convenio fue ratificado por el Senado mexicano el 17 de febrero de $1977^{4}$. Este convenio señala que la licencia pagada de estudios se concede a trabajadores, con fines educativos, por un periodo determinado, durante las horas de trabajo y como pago de prestaciones económicas adecuadas. Establece también que las autoridades públicas, las organizaciones de empleadores y de trabajadores y las instituciones u organismos dedicados a la educación o a la formación deberán aunar sus esfuerzos, según modalidades adecuadas a las condiciones y prácticas nacionales, para la elaboración y puesta en práctica de la política destinada a fomentar la licencia pagada de estudios, que La financiación de los sistemas de licencia pagada de estudios deberá efectuarse en forma regular, adecuada y de acuerdo con la práctica nacional, y que la licencia pagada de estudios no deberá negarse a los trabajadores por motivos de raza, color, sexo, religión, opinión política, ascendencia nacional u origen social.

\footnotetext{
${ }^{4}$ Diario Oficial de la Federación de 24 de marzo de 1977.
} 
En la Conferencia General de la Organización Internacional del Trabajo, de junio de 1975, se adoptó el Convenio 142, sobre la Orientación desarrollo de los recursos humanos profesional y formación profesional en el trabajo, que fue ratificado el 28 de junio de 1978 por el Senado Mexicano 5 . Este convenio señala que los países miembros de la OIT deben establecer sistemas abiertos, flexibles y complementarios de enseñanza general técnica y profesional, así como de orientación escolar y profesional y de formación profesional, tanto dentro del sistema oficial de enseñanza, como fuera de éste. También dispone que todo miembro deberá ampliar gradualmente sus sistemas de orientación profesional, incluida la información permanente sobre el empleo, a fin de asegurar que se pongan a disposición de todos los niños, adolescentes y adultos una información completa y una orientación tan amplia como sea posible, inclusive por medio de programas apropiados en el caso de los minusválidos y que Las políticas y programas de orientación profesional y formación profesional deberán establecerse e implantarse en colaboración con las organizaciones de empleadores y de trabajadores y, según los casos y de conformidad con la ley y la práctica nacionales, con otros organismos interesados.

Ambos convenios han sido actualizados por medio de convenios técnicos.

La Suprema Corte de Justicia de la Nación emitió en el año de 1999 una tesis en el sentido de que los tratados internacionales se ubicaban jerárquicamente por encima de las leyes federales y en un segundo plano respecto de la Constitución Federal'. En 2007 el Alto tribunal introdujo una modalidad al criterio sobre jerarquía normativa al señalar que los tratados internacionales son parte integrante de la Constitución de la Nación y se ubican jerárquicamente por encima de las leyes generales, federales y locales, al interpretar el artículo 133 constitucional ${ }^{7}$.

De lo anterior se deprende que los Convenios 140 y 142 son norma vigente en México y deben ser acatadas por autoridades laborales, por patrones y por trabajadores.

\section{NormatividAD MEXICANA}

\section{La Constitución Politica de los Estados Unidos Mexicanos (1917).}

Al momento de ser expedida la Constitución mexicana en 1917, no contenía disposición alguna relativa al derecho de los trabajadores ni a la obli-

\footnotetext{
${ }^{5}$ Diario Oficial de la Federación de 23 de noviembre de 1978.

${ }^{6}$ Tesis: p. Ixxvii/99. Pleno, en Semanario Judicial de la Federación y su Gaceta, X, noviembre de 1999 , p. 46.

${ }^{7}$ Tesis: IX/2007. Pleno, en Semanario Judicial de la Federación y su Gaceta. XXV, abril de 2007, p. 6.
} 
gación patronal de proporcionarles capacitación y adiestramiento. Durante muchos años los patrones que así lo consideraban adecuado, capacitaban a sus trabajadores, de conformidad con criterios que ellos mismos establecían o, en los menos de los casos, de acuerdo con los sindicatos.

\section{La Ley Federal del Trabajo (1931).}

Esta ley reguló el contrato de aprendizaje en los artículos 218 a 231.

Se entendió por contrato de aprendizaje, según el artículo 218 , aquel en el cual una persona se compromete a prestar sus servicios personales a otra, recibiendo en cambio enseñanza en un arte u oficio y la retribución convenida. De lo anterior, se deducía que entre el aprendiz y el patrón existía una relación individual de trabajo.

La retribución, en términos de la fracción II del artículo 224, podía ser en dinero en efectivo o en vestidos y alimentos. Según De la Cueva: "De este precepto se desprende que no existe obligación para el patrono de pagar un salario en numerario, lo que fácilmente se comprende, tanto porque la finalidad del aprendiz no es obtener un salario, cuanto porque no todas las empresas tienen necesidad de aprendices: no sería entonces equitativo obligar a los patrones a que acepten aprendices $y$, a la vez, les paguen una cantidad de dinero por un servicio que pueden no necesitar. El artículo que comentamos resuelve el problema que alguna vez se ha discutido de si el aprendiz tiene derecho a percibir el salario mínimo: quien está aprendiendo un oficio no puede exigir que ese oficio que ignora, le proporcione los medios de sostener a una familia, así lo resolvió la Cuarta sala en la ejecutoria de 23 de junio de 1942 , amparo directo $7.428 / 41 / 2^{a}$, Carlos Morín y coagraviados"8.

Los patrones estaban obligados a admitir como aprendices, por lo menos u cinco por ciento del total de sus trabajadores de cada oficio o profesión; si en el centro de trabajo laboraban menos de veinte trabajadores, podría haber al menos un aprendiz.

Los aprendices tenían preferencia a ser contratados al momento de surgir una vacante, según disponía el numeral 224, fracción V.

En el trabajo marítimo y ferrocarrilero no se admitían aprendices menores de dieciséis años de edad, de conformidad con el artículo 231. Por lo que hacía a otras actividades, en virtud de que la fracción III del artículo 123 de la Constitución, vigente en ese momento establecía que la edad mínima para prestar un servicio era de doce años, esa era la edad que debía respetarse en

${ }^{8}$ De la Cueva, Mario, Derecho mexicano del trabajo (México, Porrúa, 1961), p. 883. 
el caso de los aprendices. Es de destacarse que esta fracción se modificó, elevándose la edad mínima para trabajar a catorce años.

Entre las obligaciones del aprendiz, establecidas en el artículo 223, que coinciden con las de los trabajadores en general, destaca la de guardar respeto al maestro o patrono y sus familiares.

Proporcionar enseñanza, que debía ser dentro de la jornada de trabajo, era la obligación primera el patrón, la cual, si no era posible que lo hiciera personalmente, podía ser cumplida a través de algún trabajador del centro de trabajo de que se tratara.

La duración del contrato se encontraba limitado por el tiempo necesario a la enseñanza del aprendiz. Se celebraba por lo general por tiempo indeterminado y concluía en el momento en que el aprendiz había adquirido los conocimientos necesarios.

En la hipótesis de que el aprendiz fuera despedido o se separara por causa imputable al patrón, tenía derecho a un mes y medio de indemnización.

El artículo 227 determinaba que los aprendices de oficios calificados debían ser examinados cada año o cuando así lo solicitaren, por un jurado mixto de peritos obreros y patronales, presidido por un representante que designaba el inspector del trabajo; tratándose de aprendizaje marítimo, presidiría el capitán del puerto.

El propósito de esta evaluación era acreditar que el aprendiz había alcanzado la aptitud y los conocimientos que se le habían enseñado.

El numeral 229 de la Ley señalaba que los patrones estaban obligados a indemnizar a los aprendices por los riesgos profesionales que pudiesen sufrir.

\section{Ley Federal del Trabajo (1970).}

La nueva Ley Federal del Trabajo entró en vigor el 1 de mayo de 1970. No se reguló el contrato de aprendizaje. La exposición de motivos señaló que el proyecto suprimió el contrato de aprendizaje, por considerar que, tal como se encontraba reglamentado, era una reminiscencia medieval y porque, en multitud de ocasiones, era un instrumento que permitía a pretexto de enseñanza, dejar de pagar los salarios a los trabajadores o pagarles salarios reducidos; en cambio se recogió la tendencia universal en favor de cursos de capacitación profesional a cuyo fin consignó la obligación de las empresas de organizar permanentemente o periódicamente dichos cursos para sus trabajadores.

\section{La reforma constitucional de 1978.}

Fue hasta el año de 1978, el 9 de enero, en que se reformó el texto consti-

${ }^{9}$ Diario Oficial de la Federación de 21 de noviembre de 1962. 
tucional para que en el artículo 123, apartado A, fracción XIII se estableciera esta obligación patronal. Dice la norma: "XIII. Las empresas, cualquiera que sea su actividad, estarán obligadas a proporcionar a sus trabajadores, capacitación o adiestramiento para el trabajo. La ley reglamentaria determinará los sistemas, métodos y procedimientos conforme a los cuales los patrones deberán cumplir con dicha obligación".

También se reformó la fracción XXXI, en la que se contiene la competencia federal laboral, destacando que la obligación patronal de capacitación y adiestramiento queda incluida; la cual expresa: "XXXI. La aplicación de las leyes del trabajo corresponde a las autoridades de los Estados, en sus respectivas jurisdicciones, pero es de la competencia exclusiva de las autoridades federales en los asuntos relativos a: [...]; b) Empresas:/ 1. Aquéllas que sean administradas en forma directa o descentralizada por el Gobierno Federal; /2. Aquéllas que actúen en virtud de un contrato o concesión federaly las industrias que les sean conexas; y/3. Aquéllas que ejecuten trabajos en zonas federales o que se encuentren bajo jurisdicción federal, en las aguas territoriales o en las comprendidas en la zona económica exclusiva de la Nación./ También será competencia exclusiva de las autoridades federales, la aplicación de las disposiciones de trabajo en los asuntos relativos a conflictos que afecten a dos o más Entidades Federativas; contratos colectivos que hayan sido declarados obligatorios en más de una Entidad Federativa; obligaciones patronales en materia educativa, en los términos de Ley; y respecto a las obligaciones de los patrones en materia de capacitación $y$ adiestramiento de sus trabajadores, asi como de seguridad e higiene en los centros de trabajo, para lo cual, las autoridades federales contarán con el auxilio de las estatales, cuando se trate de ramas o actividades de jurisdicción local, en los términos de la ley reglamentaria correspondiente".

\section{La reforma a la "Ley Federal del Trabajo" de abril de 1978.}

Se reformó la Ley Federal del Trabajo ${ }^{10}$, en su artículo 132, fracción XV, en donde se estableció la obligación patronal de proporcionar capacitación y adiestramiento a sus trabajadores, y se adicionó el capítulo $3^{\circ}$ bis, del título $4^{\circ}$. Este capítulo reguló el derecho de los trabajadores a recibir capacitación y adiestramiento.

Se entiende por capacitación la acción y efecto de capacitar o capacitarse; capacitar es hacer a uno apto, habilitado para alguna cosa ${ }^{11}$. Adiestramiento se define como la acción y efecto de adiestrar o adiestrarse; adiestrar es hacer

${ }^{10}$ Diario Oficial de la Federación de 28 de abril de 1978, en vigencia desde el 1 de mayo del propio año.

${ }^{11}$ Diccionario de la lengua española (Madrid, Espasa Calpe, 1970), II, voz: "Capacitación”, p. 252. 
diestro, enseñar, instruir, guiar, encaminar ${ }^{12}$. Comenta Lastra: "La capacitación ha sido tradicionalmente definida como el aprendizaje que lleva a cabo una persona para superar el nivel de conocimientos, mejorar su aptitud técnica o ambas, en actividades útiles o adquirir un grado profesional en una ciencia u arte, [...] se pretende que con la capacitación el trabajador mejore sus ingresos y alcance un nivel de vida más elevado"13. De Buen, por su lado, dice: "[...] la capacitación prepara al trabajador para el desempeño de una actividad de nivel más alto de la que constituye su trabajo habitual [o uno diferente o nuevo]. El adiestramiento, en cambio, perfecciona al trabajador en el desempeño de las tareas que normalmente tiene encomendadas" ${ }^{14}$.

Entre los objetivos de la capacitación y adiestramiento se señalaba prevenir riesgos de trabajo, actualizar y perfeccionar los conocimientos y habilidades de los trabajadores e incrementar la productividad. Patrones y trabajadores debían formular de común acuerdo los planes y programas de capacitación y adiestramiento de cada centro de trabajo, los cuales debían presentarse ante la Secretaría del Trabajo y Previsión Social, para su aprobación y registro. En cada centro de trabajo era obligatorio constituir una Comisión Mixta de Capacitación y Adiestramiento, integrada de forma paritaria, la cual vigilaría la operación del sistema, sugeriría medidas tendientes a perfeccionarlo y autentificaría las constancias de habilidades laborales.

La capacitación y adiestramiento debía, en principio, impartirse dentro de la jornada de trabajo. Podía impartirse por instructores del propio centro de trabajo, por instructores específicamente contratados, dentro del propio centro de trabajo o en instituciones educativas adecuadas. Las instituciones y los instructores debían estar registrados ante la Secretaría del Trabajo y Previsión Social.

\section{La reforma a la Ley Federal del Trabajo de noviembre de 2012.}

El 1 de septiembre de 2012, el Ejecutivo Federal presentó, en ejercicio, por primera vez en la historia constitucional mexicana, de la iniciativa preferente, con fundamento en lo dispuesto por el artículo 71 de la Constitución Política de los Estados Unidos Mexicanos, que se había reformado el 9 de agosto del propio año, propuesta de reformas a la Ley Federal del Trabajo, misma que agotado el proceso legislativo en el Congreso de la Unión, se publicó en el Diario Oficial de la Federación, el 30 de noviembre, iniciando su vigencia, el 1 de diciembre.

${ }^{12}$ Diccionario de la lengua española (Madrid, Espasa Calpe, 1970), I, voz: “Adiestramiento", p. 26.

${ }^{13}$ Lastra Lastra, José Manuel (coordinador), Diccionario de Derecho del trabajo (México, Porrúa - UNAM, 2001), pp. 29-30.

${ }^{14}$ De Buen, Néstor, Derecho del trabajo (México, Porrúa, 1974), I, p. 295. 
La "Exposición de motivos", establecía, entre otros argumentos que: “Con base en los razonamientos que a continuación se exponen, avanzaremos hacia mejores niveles de bienestar. Por talmotivo sepropone:/ 1. Incorporar la noción de trabajo decente que promueve la Organización Internacional del Trabajo, para destacar los elementos que deben imperar en cualquier relación laboral, que no son otros, más que el respeto a la dignidad humana del trabajador; la no discriminación por razón de género, preferencia sexual, discapacidad, razao religión; el acceso a la seguridad social; el salario remunerador; la capacitación continua para el incremento de la productividad; la seguridad e higiene en el trabajo; la libertad de asociación; la autonomía y democracia sindical; el derecho de huelga, y la contratación colectiva. Cabe señalar que el concepto de trabajo decente a que se hace referencia, es acorde con la aspiración que nuestro texto constitucional prevé como trabajo digno./ 2. Incluir en nuestra legislación, como nuevas modalidades de contratación, los periodos de prueba, los contratos de capacitación inicial y para el trabajo de temporada, con el propósito de atender las circunstancias que privan en el mercado de trabajo. Con ello se generarán las condiciones para que un mayor número de personas, principalmente jóvenes y mujeres, puedan integrarse a puestos de trabajo en la economía formal. Estas propuestas permitirian romper el círculo vicioso en torno a que las personas no tienen empleo porque no están capacitadas y no tienen capacitación porque no cuentan con empleo./ [...]/ 16. Replantear las disposiciones que regulan la capacitación y el adiestramiento de los trabajadores, con el propósito de elevar el nivel de vida de los trabajadores y sus familias, asi como mayores rendimientos para las empresas, a través de un vinculo más estrecho entre la capacitación y la productividad. Para ello se propone:/ Rediseñar los objetivos y las tareas que tendrian a su cargo las Comisiones Mixtas de Productividad, Capacitación y Adiestramiento;/ Ampliar los objetivos de los Comités Nacionales de Productividad y Capacitación que pueden establecerse en las diferentes ramas industriales y de servicios, y en los que participan representantes de los patrones $y$ de los trabajadores, a fin de que propongan acciones para:/ Diagnosticar los requerimientos necesarios para elevar la productividad y la competitividad de las empresas; /Vincular los salarios a la calificación y competencias adquiridas;/ Estudiar mecanismos y nuevas formas de remuneración que vinculen los salarios a los beneficios de la productividad, y/Proponer la expedición de normas técnicas de competencia laboral $y$, en su caso, los procedimientos para su evaluación, acreditación y certificación" 15 .

Se modificó el artículo 35, que regula la duración de las relaciones individuales de trabajo, para incluir el periodo a prueba, el contrato de capacitación

${ }^{15}$ Cámara de Diputados del Honorable Congreso de la Unión [visible en internet: http://gaceta.diputados.gob.mx/ y consultado el 8 de diciembre de 2012]. 
inicial y el contrato por temporada; el cual quedó con la siguiente redacción: "Las relaciones de trabajo pueden ser para obra o tiempo determinado, por temporada o por tiempo indeterminado y en su caso podrá estar sujeto a prueba o a capacitación inicial. A falta de estipulaciones expresas, la relación será por tiempo indeterminado".

Se adicionó el numeral 39-A, a efecto de precisar que se entiende por período a prueba, en qué casos de contratación individual de trabajo puede incluirse, cuál es su duración, los derechos de los que debe disfrutar este trabajador y que sucede si al concluir el mismo, el trabajador no acredita los requisitos y conocimientos necesarios para desarrollar las labores para las cuales fue contratado. El artículo cobró esta forma: "En las relaciones de trabajo por tiempo indeterminado o cuando excedan de ciento ochenta días, podrá establecerse un periodo a prueba, el cual no podrá exceder de treinta dias, con el único fin de verificar que el trabajador cumple con los requisitos y conocimientos necesariospara desarrollar el trabajo que se solicita./ El periodo deprueba a que se refiere el párrafo anterior, podrá extenderse hasta ciento ochenta días, sólo cuando se trate de trabajadores para puestos de dirección, gerenciales y demás personas que ejerzan funciones de dirección o administración en la empresa o establecimiento de carácter general o para desempeñar labores técnicas o profesionales especializadas./ Durante el periodo de prueba el trabajador disfrutará del salario, la garantía de la seguridad socialy de las prestaciones de la categoría o puesto que desempeñe. Al término del periodo de prueba, de no acreditar el trabajador que satisface los requisitos y conocimientos necesarios para desarrollar las labores, a juicio del patrón, tomando en cuenta la opinión de la Comisión Mixta de Productividad, Capacitacióny Adiestramiento en los términos de esta Ley, así como la naturaleza de la categoría o puesto, se dará por terminada la relación de trabajo, sin responsabilidad para el patrón".

También se adicionó el artículo 39-B, en el cual se establece qué se entiende por capacitación inicial, qué vigencia puede tener en función de las actividades a desempeñarse por el trabajador contratado en esta modalidad, los derechos de los que gozará el trabajador, y qué sucederá si al término de la capacitación inicial el trabajador no acredita la competencia exigida. El artículo 39-B resultó así: "Se entiende por relación de trabajo para capacitación inicial, aquella por virtud de la cual un trabajador se obliga a prestar sus servicios subordinados, bajo la dirección y mando del patrón, con el fin de que adquiera los conocimientos o habilidades necesarios para la actividad para la que vay a a ser contratado./ La vigencia de la relación de trabajo a que se refiere el párrafo anterior, tendrá una duración máxima de tres meses o en su caso, hasta de seis meses sólo cuando se trate de trabajadores para puestos de dirección, gerenciales y demás personas que ejerzan funciones de dirección o administración en la empresa o establecimiento de carácter general o para desempeñar labores 
que requieran conocimientos profesionales especializados. Durante ese tiempo el trabajador disfrutará del salario, la garantía de la seguridad social y de las prestaciones de la categoría o puesto que desempeñe. Al término de la capacitación inicial, de no acreditar competencia el trabajador, a juicio del patrón, tomando en cuenta la opinión de la Comisión Mixta de Productividad, Capacitación y Adiestramiento en los términos de esta Ley, asi como a la naturaleza de la categoría o puesto, se dará por terminada la relación de trabajo, sin responsabilidad para el patrón".

También se adicionó el numeral 39-C que establece la obligación de que esas modalidades de contratación, periodo prueba y capacitación inicial, se formalicen por escrito, omisión que tendrá por resultado que la relación de trabajo se considere celebrada por tiempo indeterminado: "La relación de trabajo con periodo a prueba o de capacitación inicial, se hará constar por escrito garantizando la seguridad social del trabajador; en caso contrario se entenderá que es por tiempo indeterminado, y se garantizarán los derechos de seguridad social del trabajador".

La adición del artículo 39-D tuvo como objeto establecer que los periodos a prueba y la capacitación inicial que se convengan entre patrón y trabajador, son improrrogables, al igual que no es factible celebrarlos en forma sucesiva o simultánea, en un mismo centro de trabajo, en relación a un mismo trabajador, aun cuando fuesen puestos de trabajo diversos. El nuevo artículo 39-D dijo: "Losperiodos a pruebay de capacitación inicial son improrrogables./ Dentro de una misma empresa o establecimiento, no podrán aplicarse al mismo trabajador en forma simultánea o sucesiva periodos de prueba o de capacitación inicial, ni en más de una ocasión, ni tratándose de puestos de trabajo distintos, $o$ de ascensos, aun cuando concluida la relación de trabajo surja otra con el mismo patrón, a efecto de garantizar los derechos de la seguridad social del trabajador".

Finalmente se adicionó el artículo 39-E, a efecto e establecer que si vencidos los plazos de la contratación inicial o del periodo a prueba, subsiste la relación de trabajo, esta se considerará por tiempo indeterminado. El artículo 39-E preceptuó: "Cuando concluyan los periodos a prueba o de capacitación inicial y subsista la relación de trabajo, ésta se considerará por tiempo indeterminado y el tiempo de vigencia de aquellos se computará para efectos del cálculo de la antigüedad".

La reforma incluyó modificaciones al capítulo $3^{\circ}$ bis, del título $4^{\circ}$ de la Ley. La denominación del capítulo cambió, pues dejó de ser: "De la capacitacióny adiestramiento de los trabajadores" para rezar: "Dela productividad, formación y capacitación de los trabajadores". Comprende del artículo 153-A al 153-X.

La disposición en el sentido de que la capacitación que era un derecho de los trabajadores, se transformó en una obligación de los patrones, según se establece en el artículo 153-A. 
En relación a que la capacitación o adiestramiento, ésta debe ser impartida, en principio, dentro de la jornada de trabajo, pudiendo ser dentro o fuera del centro de trabajo. Se impartirá por personal de la propia empresa o por personal expresamente contratado para ello, por instituciones o escuelas u organismos especializados, Los cursos y programas de capacitación o adiestramiento de los trabajadores, podrán formularse respecto de cada establecimiento, una empresa, varias de ellas o respecto a una rama industrial o actividad determinada, también en términos del artículo 153-A.

Los instructores deben contar con el registro correspondiente ante la Secretaría del Trabajo y Previsión Social, de conformidad con el numeral 153-G.

Según se dispone en el artículo 153-B, la capacitación debe tener por objeto preparar a los trabajadores de nueva contratación y a los demás interesados en ocupar las vacantes o puestos de nueva creación. También pueden formar parte de los programas de capacitación el apoyo que el patrón preste a los trabajadores para iniciar, continuar o completar ciclos escolares de los niveles básicos, medio o superior.

$\mathrm{El}$ adiestramiento tiene por objeto, tanto actualizar y perfeccionar los conocimientos y habilidades de los trabajadores, como hacer del conocimiento de los trabajadores sobre los riesgos y peligros a que están expuestos durante el desempeño de sus labores, así como las disposiciones contenidas en el reglamento y las normas oficiales mexicanas en materia de seguridad, salud y medio ambiente de trabajo, como incrementar la productividad y, en general, mejorar el nivel educativo, la competencia laboral y las habilidades de los trabajadores. Lo anterior, de conformidad con el artículo 153-C.

La Ley Federal el Trabajo, hasta el 30 de noviembre de 2012, exigía que en cada empresa debían constituirse Comisiones Mixtas de Capacitación y Adiestramiento, integradas por igual número de representantes de los trabajadores y del patrón, las cuales vigilarán la instrumentación y operación del sistema y de los procedimientos que se implanten para mejorar la capacitación y el adiestramiento de los trabajadores, y sugerirán las medidas tendientes a perfeccionarlos; todo esto conforme a las necesidades de los trabajadores y de las empresas. Después de la reforma, ésta es una obligación únicamente, para las empresas que tengan más de 50 trabajadores, por lo que conformidad con el numeral 153-E, se constituirán Comisiones Mixtas de Capacitación, Adiestramiento y Productividad, integradas por igual número de representantes de los trabajadores y de los patrones.

Subsistió la obligación de elaborar planes y programas, con la diferencia de que antes de la reforma, estos se debían presentar ante la Secretaría del Trabajo y Previsión Social para su aprobación. La normatividad vigente, establece que es obligación de los patrones conservar, según el artículo 153F Bis a disposición de la misma autoridad y la Secretaría de Economía, los 
planes y programas de capacitación, adiestramiento y productividad que se hubiesen acordado establecer, o en su caso, las modificaciones que se hayan convenido acerca de planes y programas ya implantados.

Las nuevas disposiciones incluyeron el concepto de productividad en el artículo 153-I, que no se contemplaba antes de la reforma. Se entiende por productividad, el resultado de optimizar los factores humanos, materiales, financieros, tecnológicos y organizacionales que concurren en la empresa, en la rama o en el sector para la elaboración de bienes o la prestación de servicios, con el fin de promover a nivel sectorial, estatal, regional, nacional e internacional, y acorde con el mercado al que tiene acceso, su competitividad y sustentabilidad, mejorar su capacidad, su tecnología y su organización, e incrementar los ingresos, el bienestar de los trabajadores y distribuir equitativamente sus beneficios. Se dispone que al establecimiento de los acuerdos y sistemas para medir e incrementar la productividad, concurrirán los patrones, trabajadores, sindicatos, gobiernos y academia.

La ley dispone que, de conformidad con el artículo 153-K, la Secretaría del Trabajo y Previsión Social, en conjunto con la Secretaría de Economía, convocarán a los patrones, sindicatos, trabajadores e instituciones académicas para que constituyan el Comité Nacional de Productividad, que tendrán el carácter de órgano consultivo y auxiliar del Ejecutivo Federal y de la planta productiva. Anteriormente se constituían Comités Nacionales de Capacitación y Adiestramiento.

Si algún patrón no da cumplimiento a la obligación de conservar a disposición de la Secretaría del Trabajo y Previsión Social los planes y programas de capacitación y adiestramiento, o cuando dichos planes y programas no se lleven a la práctica, será sancionado, como dispone el artículo 153-S, sin perjuicio de que, en cualquiera de los dos casos, la propia Secretaría adopte las medidas pertinentes para que el patrón cumpla con la obligación de que se trata. Se le impondrá una multa de 50 a 5000 veces el salario mínimo general, al patrón que no cumpla con lo dispuesto en la fracción XV del artículo 132.

El artículo 153-T dispone que los trabajadores que hayan sido aprobados en los exámenes de capacitación y adiestramiento, tendrán derecho a que la entidad instructora les expida las constancias respectivas, mismas que, autentificadas por la Comisión Mixta de Capacitación y Adiestramiento de la Empresa, se harán del conocimiento de la Secretaría del Trabajo y Previsión Social, por conducto del correspondiente Comité Nacional o, a falta de éste, a través de las autoridades del trabajo a fin de que la propia Secretaría las registre y las tome en cuenta al formular el padrón de trabajadores capacitados que corresponda, en los términos de la fracción IV del artículo 539, de la propia ley.

Adicionalmente a las Comisiones Mixtas de Capacitación, Adiestra- 
miento y Productividad que se integren en cada centro de trabajo con más de 50 trabajadores, se constituirá el Comité Nacional de Productividad y la Comisión Nacional de Productividad, que tendrán competencia en todo el territorio nacional, según disponen los artículos 153-K y 153-L.

La Comisión Nacional de productividad establecerá subcomisiones sectoriales, por rama de actividad, tanto estatales como regionales, en acatamiento al numeral 153-N. También deberán establecerse Comisiones Estatales de Productividad, en las entidades federativas del país, según el numeral 153-Q.

En el proceso de negociación y contratación colectiva, deberán, patrón y sindicato, incluir cláusulas relativas a la obligación patronal de proporcionar capacitación y adiestramiento a los trabajadores, conforme a planes y programas vigentes o que se diseñen más adelante. También podrá consignarse en los propios contratos el procedimiento conforme al cual el patrón capacitará y adiestrará a quienes pretendan ingresar a laborar en la empresa, tomando en cuenta, en su caso, la cláusula de admisión. Ello, con fundamento en al artículo 153-M.

Los certificados, diplomas, títulos o grados que expidan el Estado, sus organismos descentralizados o los particulares con reconocimiento de validez oficial de estudios, a quienes hayan concluido un tipo de educación con carácter terminal, serán inscritos en los registros de que trata el artículo 539, fracción IV, cuando el puesto y categoría correspondientes figuren en el Catálogo Nacional de Ocupaciones o sean similares a los incluidos en él, en acatamiento al artículo 153-W.

En el supuesto de que las partes consideran que la contraria ha incumplido con sus obligaciones, en términos del numeral 153-X, tienen derecho a ejercitar ante las Juntas de Conciliación y Arbitraje las acciones individuales y colectivas que deriven de la obligación de capacitación o adiestramiento

\section{OPINIÓN DE LOS TRIBUNALES DE AMPARO}

El Primer Tribunal Colegiado en materia Administrativa y Civil del Décimo Cuarto Circuito del Poder Judicial en México, dictó en materia administrativa una tesis aislada, la cual sostiene que de los artículos 132, fracción XV [fracción que no fue modificada en la reforma de noviembre de 2012] y 994, fracción IV [fracción que fue modificada por lo que corresponde al monto de la multa], de la Ley Federal del Trabajo, se advierte que existe obligación del patrón de proporcionar capacitación y adiestramiento a los trabajadores que estén a su servicio, cuyo incumplimiento conlleva la imposición de una multa de quince a trescientas quince veces el salario mínimo general. Ahora bien, conforme a ese marco normativo, la obligación patronal de referencia es única y se circunscribe estrictamente a cuestiones propias de capacitación 
y adiestramiento de los trabajadores, por lo que jurídicamente resulta ilegal aplicar una pluralidad de multas por faltas en esa materia, ya que las diversas omisiones en que pueda incurrir el patrón, necesariamente se traducen en el incumplimiento de la obligación mencionada, y en esas condiciones, es inconcuso que sólo procede la imposición de una multa por desacato a lo previsto en la fracción XV del artículo 132 de la Ley Federal del Trabajo ${ }^{16}$.

El Tercer Tribunal Colegiado del Primer Circuito, dictó tesis aislada en materia laboral, señalando que la interpretación armónica de los artículos 123, apartado A, fracción XXXI, inciso b), último párrafo, de la Constitución Federal, 51, fracción VII, 527, 529, 698 y 699 de la Ley Federal del Trabajo, permite considerar que en tratándose de una demanda en la que se reclama la rescisión de la relación laboral por causas imputables al patrón sin responsabilidad para los trabajadores, que se hace consistir en que la fuente de trabajo presenta condiciones de alto riesgo de sufrir un accidente, de adquirir enfermedades profesionales por no proporcionárseles la capacitación necesaria, ni el equipo de seguridad para el desempeño de sus actividades, por imperativo de los principios constitucionales establecidos en el numeral aludido, acogidos por la propia Ley Federal del Trabajo, es competente para conocer de la controversia la Junta Federal de Conciliación y Arbitraje; por ende, cuando en la demanda se ejerciten acciones relacionadas con obligaciones patronales en materia de capacitación y adiestramiento o de seguridad e higiene, y la misma es presentada ante una Junta Local de Conciliación y Arbitraje, en atención a que la competencia es una cuestión de orden público y, por consecuencia, su observancia es obligatoria, dicha Junta, al proveer sobre la admisión de la demanda, deberá ordenar sacar copia de la misma, así como de los documentos presentados por el actor, los que remitirá en forma inmediata a la Junta Federal para su sustanciación y resolución, exclusivamente, de las cuestiones sobre capacitación y adiestramiento, seguridad e higiene ${ }^{17}$.

El Primer Tribunal Colegiado del Octavo Circuito resolvió en una tesis aislada en materia laboral que la disposición contenida en el artículo 25, fracción VIII, de la Ley Federal del Trabajo, [fracción no modificada por la reforma indicada], consistente en la indicación de que el trabajador será capacitado o adiestrado en los términos de los planes y programas que establezca la empresa conforme a la ley, es una obligación formal que debe estar contenida expresamente en el contrato individual, por ser éste el documento en el que constan las condiciones de trabajo, pues el hecho de que una de sus cláusulas remita a las normas legales y reglamentarias respectivas, no basta

${ }^{16}$ Tesis XIV, 1' , A.C. 1 A, en Semanario Judicial de la Federación y su Gaceta, XXV, enero de 200, p. 2.268.

${ }^{17}$ Tesis XI. 3º, 13 L, en Semanario Judicial de la Federación y su Gaceta, XVI, septiembre de 2002, p. 1.387. 
para dar cumplimiento a esta obligación, ya que es obvio que el legislador quiso que constara expresamente dicha indicación en el contrato en el que se establecen las condiciones de trabajo, pues utiliza la frase "deberá indicar", la cual no es potestativa ${ }^{18}$.

\section{OPINIÓN DE LOS DESTINATARIOS DE LA NORMATIVIDAD}

$\mathrm{Al}$ analizar una normatividad como la que aquí se trata, la metodología de la investigación ${ }^{19}$ establece que en un estudio de la naturaleza de éste se debe empezar por saber quiénes son los destinatarios de la misma y, en consecuencia, se debe saber quiénes van a ser medidos, lo cual implica saber cuál es la unidad de análisis.

Después se debe proceder a delimitar la población que va a ser estudiada y sobre la cual se pretende generalizar los resultados. Se define la muestra como un subgrupo de la población. Para seleccionar la muestra, deben limitarse las características de la población, la cual puede ser probabilística y no probabilística. Esta última, también llamada muestra dirigida, a su vez, puede ser por cuotas o intencional ${ }^{20}$.

Para este estudio se optó por una muestra no probabilística intencional, es decir, se seleccionaron casos representativos de la población estudiada. Siendo la unidad de análisis trabajadores cuya relación laboral se regula por la Ley Federal del Trabajo, se encuestó, en el mes de mayo de 2013, en Mexicali, Baja California, México, a cien personas que prestan sus servicios en diversos giros, en este caso, tienda de abarrotes, zapatería, papelería, tienda de ropa, óptica, librería, taller mecánico, salón de belleza, restaurante, imprenta, lavandería, agencia de viajes, mueblería, farmacia, estudio fotográfico y cuya relación laboral que les une con su patrón, se rige por la Ley Federal del Trabajo.

Los resultados obtenidos fueron:

i) El $65 \%$ dijo estar contratado por tiempo indeterminado y el $35 \%$, que por tiempo u obra determinados.

ii) El 83 \% expresó que le explicaron las actividades a realizar al momento de la contratación y el $17 \%$ manifestó que le indicaron que los otros trabajadores le explicarían sus actividades.

iii) El $72 \%$ señaló que le pidieron referencias antes de contratarlo.

${ }^{18}$ Tesis VIII, $1^{\circ}, 17$ L, en Semanario Judicial de la Federación y su Gaceta, V, enero de 1997, p. 446.

${ }^{19}$ Hernández SAmpieri, Roberto y otros, Metodología de la Investigación (México, McGraw Hill., 2001), pp. 204 ss.

${ }^{20}$ Rojas Soriano, Raúl, Guia para realizar Investigaciones Sociales (México, UNAM, 1979), pp. 171 ss. 
iv) El 0\% manifestó haber participado en la elaboración de planes y programas de capacitación y adiestramiento.

v) El 0\% dijo que en su centro de trabajo podía opinar sobre la capacitación y adiestramiento que necesitara.

vi) El 12\% manifestó que en su centro de trabajo le permiten asistir a alguna escuela.

vii) El 0\% dijo que en su centro de trabajo se imparte Primaria abierta.

viii) El $87 \%$ señaló que le gustaría acudir a instituciones educativas, para capacitarse $\mathrm{o}$ adiestrarse, sin costo.

ix) El 93\% señaló que le gustaría que su patrón ofreciera suficientes cursos de capacitación y adiestramiento.

La entrevista es una situación interpersonal, de conversación entre dos o más personas, en la que participa una persona preguntando y la otra u otras, responden. Es un instrumento para recolectar información que permite profundizar sobre un tema determinado; puede ser estructurada o abierta ${ }^{21}$. La entrevista estructurada es aquella en la cual se definen previamente los temas específicos sobre los cuales se recoge información. La entrevista abierta es aquella que se utiliza cuando se empieza a recabar información, es decir, cuando no se cuenta con datos, sobre el objeto de estudio.

Se optó por la entrevista estructurada, aplicándose a quince patrones, cuyos giros de trabajo son tienda de abarrotes, zapatería, papelería, tienda de ropa, óptica, librería, taller mecánico, salón de belleza, restaurante, imprenta, lavandería, agencia de viajes, mueblería, farmacia, estudio fotográfico y cuya relación laboral que les une con sus trabajadores, se rige por la Ley Federal del Trabajo.

Los resultados obtenidos fueron:

i) El 43\% contestó que al contratar trabajadores no les exigen conocimientos previos en relación al trabajo a desempeñar.

ii) El 6\% dijo que les proporcionan capacitación a los trabajadores de nuevo ingreso.

iii) El 16\% manifestó que a los trabajadores que ya laboran en el centro de trabajo, les proporcionan cursos de adiestramiento.

iv) El 0\% dijo que la Comisión Mixta de Capacitación y Adiestramiento está integrada en el centro de trabajo.

$v)$ El $0 \%$ dijo que se han elaborado, registrado y difundido los planes y programas de capacitación y adiestramiento.

vi) El 0\% manifestó haber sido requerido en alguna ocasión por la Ins-

${ }^{21}$ Giraldo Ángel, Jaime y otros, Metodología y técnica de la investigación sociojurídica (México, Legis, 1999), pp. 98 ss. 
pección del Trabajo, en relación a sus obligaciones de capacitar y adiestrar a sus trabajadores.

vii) El 0\% señaló que autoriza a sus trabajadores a asistir a instituciones educativas, durante una parte de su jornada de trabajo.

viii) El 87\% dijo estar dispuesto a pagar algún impuesto, para liberarse de la obligación de capacitar y adiestrar a sus trabajadores.

ix) El 87\% señaló estar de acuerdo en que el Estado asuma el compromiso de capacitar y adiestrar a sus trabajadores, financiando esta actividad con el impuesto pagado por los patrones.

\section{REFLEXIONES FINALES}

La formación para el trabajo es un factor que permite el desarrollo de los seres humanos como trabajadores y como ciudadanos, contribuyendo al avance económico del país.

La educación técnica y el mundo laboral deben acercarse, trabajar en equipo. Desafortunadamente en la mayoría de los centros de trabajo no se cumple con la constitución de las comisiones mixtas de capacitación y adiestramiento, ni tampoco con la elaboración de los planes y programas correspondientes.

La figura del contrato de capacitación inicial no se ha aprovechado como el legislador consideró, ni tampoco ha generado el número de empleos nuevos que incidieran sobre la tasa de desempleo en el país.

Por lo anterior, lo que se hace, para resolver el problema o cumplir con la obligación es organizar cursos en el propio centro de trabajo, o celebrar convenios con instituciones educativas y enviar a los trabajadores a cursarlos. Por lo general estos cursos no se seleccionan en base a los requerimientos de capacitación y adiestramiento de la empresa y de los trabajadores, sino en función de la disponibilidad de los instructores, los horarios en que se ofertan o, incluso, el costo que representan.

Por lo anterior, no se capacita adecuadamente a los trabajadores. Deben encontrarse soluciones factibles y útiles a esta problemática.

Las opciones son desde instalar duplicados de empresas en los centros escolares, intensificar la formación de los alumnos en un puesto laboral, en lugar de limitarse a cursos de capacitación y adiestramiento impartidos en los centros de trabajo o, aun, en instituciones educativas, pero que suelen estar desvinculados del mundo laboral real, a pesar de que se pudiesen impartir en cumplimiento de los planes y programas de capacitación.

Por lo anterior, con fundamento en el Convenio 142 de la OIT y las opiniones de trabajadores y patrones, resulta necesario que en México, se constituya un organismo rector de la formación de mano de obra capacita- 
da en el país. Deberá ser un organismo descentralizado, con personalidad jurídica, patrimonio propio, autonomía presupuestal, sectorizado a la Secretaría del Trabajo y de la Previsión Social, constituido como organismo fiscal autónomo.

En virtud de que la capacitación y adiestramiento es una obligación patronal, el régimen de financiamiento de este organismo deberá ser mediante la aportación que éstos hagan a un fondo nacional del $1 \%$ del salario pagado a sus trabajadores, que estará a cargo del organismo antes referido y cuya función será organizar, instrumentar, coordinar, validar, establecer requisitos de ingreso, permanencia y egreso, determinar equivalencias, expedir certificados, todo relacionado con la capacitación y adiestramiento a nivel nacional

\section{BiBLIOgRAFÍA}

Cázares García, Gustavo, Derecho de la seguridad social (México, Porrúa, 2001).

Charny, Hugo, voz “Aprendiz”, en Enciclopedia Jurídica Omeba (Buenos Aires, Bibliográfica Omeba Driskill, 1979), I,A.

De Buen, Néstor, Derecho del trabajo. (México, Porrúa, 1974), I.

De la Cueva, Mario, Derecho mexicano del trabajo (México, Porrúa, 1961).

Diario Oficial de la Federación

Diccionario de la lengua española. (Madrid, Espasa Calpe, 1970), I.

Giraldo Ángel, Jaime y otros, Metodología y técnica de la investigación sociojurídica. (México, Legis, 1999).

Hernández Sampieri, Roberto y otros, Metodología de la Investigación (México, McGraw Hill., 2001).

Kanawaty, George, Introducción al estudio del trabajo (México, Organización Internacional del Trabajo - Noriega Editores. 2006).

Lastra Lastra, José Manuel (coordinador), Diccionario de Derecho del trabajo. (México, Porrúa - UNAM, 2001).

Rojas Soriano, Raúl, Guía para realizar Investigaciones Sociales. (México, UNAM, 1979).

Semanario Judicial de la Federación y su Gaceta. 